\title{
Review and Critique of the TATA-BOX Model
}

\author{
Charles A. Francis and Geir Lieblein
}

\begin{abstract}
The TATA-BOX model provides a practical and operational set of methods for helping multiple stakeholders design an agroecological transition at the local level. It provides a framework for researchers to study current methods and design future systems based on ecological principles. In contrast to extreme technology-driven agriculture and globalisation of food systems, this strategy returns control to the local level. Location-specific planning provides an imaginative model for sustainable development, building potential to overcome crippling bureaucracy of governments and tyranny of narrowly vested interests that result from a "productionist model" that has prevailed over the past century. The new model based on "post-normal science" is defined in terms of participatory, integrated assessment, involving all stakeholders in local development, working in transdisciplinary teams. The process addresses "wicked", complex current and future challenges today, problems involving multiple people and incommensurate goals. This requires careful study, reasoned discussion, and thoughtful compromise to reach common ground. Principles include holistic thinking, whole systems focus in the local context, involving multiple stakeholders, local autonomy, linking production with consumption in local food systems, and broad-based governance at the community, landscape, and terroir levels. This can assure participation in decision making, and action, leading to adoption of transformative systems.
\end{abstract}

\footnotetext{
C. A. Francis $(\bowtie)$

Department of Agronomy and Horticulture, University of Nebraska-Lincoln, Lincoln, NE, USA

Department of Plant Science (IPV), Norwegian University of Life Sciences, Aas, Norway e-mail: cfrancis2@unl.edu

G. Lieblein

Department of Plant Science (IPV), Norwegian University of Life Sciences, Aas, Norway

e-mail: Geir.Lieblein@nmbu.no
} 


\section{Foreword}

The TATA- BOX model includes "an operational set of articulated methods for supporting stakeholders to design an agroecological transition at local level", and provides guidelines for researchers to design future systems based on ecological principles following strategies currently used in education and research. These currently fall under the umbrella term agroecology, defined variously as "the ecology of food systems" (Francis et al. 2003) or "a science, a set of practices, or a movement" (Wezel et al. 2009). As an overview, whatever the definition, the concepts and applications of ecological principles in design of agricultural production and food systems have come to predominate among today's progressive researchers and educators. The book's authors present this model as an alternative that provides stark contrast to the current dominant globalisation of agriculture and food, and articulate a strategy that returns control to the local level. What is presented in this book is an imaginative and practical alternative model for sustainable development, one that can overcome the bureaucracy of governments and tyranny of narrow vested interests that have resulted from the "productionist model" that has grown to prevail over the past century. It is a pleasure to evaluate the details of this new model and reinforce the authors' emphasis on education at all levels in moving its implementation.

The authors describe their approach as rooted in "post-normal science" which is defined in terms of its paradigm in "participatory integrated assessment" and which is involved in solving the "wicked challenges" (Ostrom 2009) of tomorrow that can only be addressed by multi- or transdisciplinary teams. These challenges are often considered to be incommensurable, in that no solution may be available that will meet the needs of all involved stakeholders, and thus it is essential to compromise and spend major effort in finding common ground. Such solutions to problems are at the other end of the spectrum from the "technical packages" of seed, fertiliser, and pesticide that were the basis of the successful Green Revolution which increased production in the most favourable areas for agriculture. Because of narrow focus on short-term production and economic gains, scientists and development experts created a number of secondary problems due to inattention to distribution of benefits, and how this use of technology in agriculture may have contributed to greater economic and social disparities in many places where it was applied with apparent and immediate success. The philosophy behind the TATA-BOX model includes anticipating these challenges in order to contribute to sustainable development in farming and food systems.

A logical method of approaching a critique and evaluation is to move through the document one section and chapter at a time, and then to provide an overview at the end. The TATA-BOX strategy is a valuable contribution to the future of sustainable development, although it is important to not create yet another strict model that would introduce a more broad-based yet still top-down method with strong government or regional control. It is important to remember that the phenomena in farming and food systems are always richer than the lens we put up to observe them. The farm is always more than the model. A valuable feature of the model presented is the emphasis on shared and broad governance. It is important to avoid "monoculture 
thinking", and to avoid another one-size-fits-all methodology that is the opposite of what is learned from ecology and the special potentials and characteristics of every agroecological niche, including its biophysical and socioeconomic uniqueness compared to others. At the same time, it is recognised that there are processes and methods that can be generalised, based on ecological principles, as long as these are not squeezed into some artificial framework that becomes a comfort zone that can cause those in agricultural development to think the job is done now that a new and special model has been developed. Here is an evaluation of each of the sections.

\section{Introduction}

The authors begin with an overview of major challenges that have resulted from a productionist philosophy and focus on improving agricultural practices and the efficiency of input use in the process. This is a laudable strategy that they call a "weak ecological modernisation", one that appears frequently in the literature as "ecointensification" and is often used as a term to describe improvements in fine-tuning today's production systems. It should be noted that E.U. countries in general appear to have progressed more rapidly in the implementation of this strategy than other countries such as the U.S. where pressure by large-scale farm owners supported by narrow-thinking federal support programs continue to encourage maximum production, in spite of diminishing returns to inputs and a glut in the market for major commodity crops. In contrast, the authors here propose a "strong ecological modernisation" that includes a broader and more comprehensive set of goals such as improving the understanding of system properties and interactions. These go beyond the biophysical and short-term economic evaluation of system outputs to include their environmental and social impacts. They emphasise social values, improvement through learning and experimentation, encouraging participation by all actors involved in food systems, and recognising the importance of governance at all levels of scale. The authors discuss the importance of diversified and integrated systems that build on synergies among the components, and discuss the Socio Ecological System (SES) and Socio Technical System (STS) frameworks that deal with governance of resources and the dynamics of innovation in what are essentially "human activity systems" (Checkland and Scholes 1999) (term not included in the chapter). There is strong emphasis placed on uniqueness of place, recognition of boundaries around specific areas of inference for application of new technologies, and the "adaptive governance" needed to adjust decisions to an increasingly volatile natural and economic climate. There is much value in this approach.

What are perhaps ignored in this overview are other important dimensions of the food system that must be considered. There is an abundance of food produced on a global scale, but $30-45 \%$ of this is not consumed by people due to losses in the field (more often in Third World) or wasted in the system of marketing, transport, or consumption (more often in First World). Another inefficiency not considered in the introduction is the massive production of animal protein in confined operations that 
use inordinate amounts of grain, water, and other resources, especially those producing meat from ruminant livestock that did not evolve to consume that type of diet. Another misallocation of cereal grains is production of biofuels, a luxury that may raise prices a small amount to help farmers but a strategy far less desirable than conservation of fuels and development of renewable resources to replace fossil fuels. Yet another example of poor allocation is the documented obesity epidemic worldwide, with more people overweight than undernourished at this point in time. The importance of spatial availability of food, and the lack of access by those in poverty conditions must be considered in the assessment matrix of any food system, when this is viewed at the global or any level.

Those who developed the TATA-BOX have done this in the context of Europe, and that is commendable. Yet there are broader issues that are obvious in the developing South that are also important in the developed world that need to be considered in any future strategy that will lead to people being able to produce or access food with a degree of sovereignty or control of their own diets. These are wide nutritional and food issues, and it would be valuable to put the new techniques into proper perspective at local as well as regional and global levels.

\section{TATA-BOX at a Glance}

The context of the project is briefly reviewed, before the authors move into a literature review about the history of design techniques based on conceptual frameworks of food system development. The idea of dividing "materials resources" into those from natural resources, farming systems, and supply chains may be confusing to some readers, since the second and third of these in most languages are considered human constructs that are quite different from the biophysical input resources that go into production agriculture. It may be a translation question, but perhaps a better term than "material resources" here could be "natural and human systems resources" to be more inclusive and to help understanding by a broader audience.

Aside from this semantic challenge, the thinking process described and model illustrated both show the connectivities of social and biological components and importance of diversity in each provides a strong conceptual foundation for understanding complexity. The idea of "backcasting" from a future desirable situation to today's reality, and the multiple paths that could lead to success mirror the approach we have taken in agroecology education and research in Norway and Nebraska (Lieblein et al. 2001, 2004; Francis et al. 2016). Depicting this in a colourful visual is an effective device for communication and building understanding.

Details on the scope and organisation of the project are illustrative to the reader, and help to build confidence in the results, but are not particularly germane to the flow of the discussion. It is recognised that these are essential components of a project report and should be maintained in the text if that is one of the purposes of the book. 


\section{Socio-economic Characterisation of Agriculture Models}

This useful chapter explains a new typology that includes six models based on "social principles and moral values", in contrast to most categorisations in the literature that only include two types that greatly oversimplify the discussion. The authors begin with descriptions of a number of contemporary models that illustrate this contrast, citing references to "shallow and deep sustainability", "weak versus strong multifunctionality", "weak versus strong ecological modernisation of agriculture", and "life sciences versus an agroecology vision". They rightly recognise the simplicity of creating such dualism in characterising systems, and how such constructs for comparison tend to set up a "straw-man" system against which a better one may be compared, in the opinions of each author. Although they see use in such models, the authors feel that these often ignore some of the most important elements or characteristics that include the impact of social values on decision making, and that moral values and social principles should have a higher profile. To meet this challenge, they propose that multiple analysis frameworks should include agronomic and physical characteristics to be combined with socio-economic criteria, and thus a need for more models of greater complexity and improved inclusivity of measures that really matter.

The first section deals with sustainable agriculture in terms of socio-economic factors and how social values should be considered as a broader approach to assessing the worth of a system and how these influence decisions. The authors build on a construct from political philosophy that categorises cities based on wealth, efficiency, equity, honesty, grace, and fame, and add their own category of cities "based on the principle of good intentions directed at the environment" (Chapter 3, p. 4). People who live in these "cities" or communities of common interest use such values to "organise collective action" and support institutions to design activities consistent with values. They recognise that goals are often incommensurate, and that compromise is essential for harmonious action. Criteria for evaluating these contrasting "cities" or world views are summarised in an illustrative table, and the process then related to agriculture and the choice of practices or strategies. As these relate to the current interest in multifunctional landscapes and agriculture as a key component, the categories provide a framework for evaluation and how this will impact the continued potential success of chosen systems.

A second section describes models that interface production and food systems, and introduces the essential element of local social dynamics in the complex process of choosing internal versus external inputs, deciding on importance of ecoservices, and putting emphasis on local versus global orientation of the food system - at any level of scale. They set up a somewhat tenuous comparison of sources of inputs versus ecoservices as indicators of the degree of sustainability. The authors rightly describe systems based on internal resources and clever design to make use of natural processes as more complex than the "domination and control" model of using pesticides and fertilisers to run a successful production system. And they bring this idea full circle when suggesting that managing systems using natural diversity and 
considering ecoservices as an input rather than a consequence of systems performance. It's a complicated reasoning that is difficult to grasp, at least in a practical agronomic sense. The authors move on to describe the contrast between (1) local sources to purchase inputs and global markets for product sale and (2) the integrated systems now in vogue of agroforestry, multi-cropping and mixed farming systems incorporating animals, and conservation agriculture. They rightly maintain that global and local markets are complementary, and few would argue that in most places these will continue to exist and interact, especially in the developed world.

The last section characterises models based on socio-economic criteria and contrasts six alternatives to the "historical-conventional system" or (1) "productionist model" currently prevalent in the North and in some favoured areas with good resources and infrastructure in the developing world. This is compared to (2) a technology-intensive model, (3) a techno-domestic model, (4) a circular model, (5) a diversified-globalised model, (6) a diversified local model, and (7) a diversified integrated landscape model. All include different degrees of technology use, integration with "global" input sources and markets, and dependence on natural systems and local ecoservices for driving the system. It jumps out to us that model (7) is the preferred ideal from the agroecologists point of view, and that this is the "gold standard" to strive for in achieving long-term, lasting, and equitable outcomes that will benefit all stakeholders in the agriculture and food system.

The chapter concludes with describing the value of these models and how understanding them could inform decisions on public policy. Without making a value judgement on which systems are necessarily most desirable for the future, it is clear that the choice of any one system or combination of elements from several systems will depend on the world views of the stakeholders in a given location. The authors point out the importance of making explicit the goals of people in a particular situation, recognising that the socio-economic reality of each place may be different, and that development of effective policy will be most successful if values are known and made explicit. The ideas of multi-criteria assessment, incommensurable goals of the players in each place, and difficulties in clearly envisioning the constraints that will face people in designing future agriculture and food systems are brought into focus in the chapter.

One is faced with the ultimate question of, "So what"? Is there a framework or series of potential frameworks here that can provide some clarity to analysing systems, making the interactions of their components more understandable, and ultimately leading to more appropriate actions? Are there vested economic and political interests that are so powerful in many locations that make this type of analysis moot in the face of larger pressures that complicate decisions and present naïve strategies that are unlikely to be useful. As with any analysis, there are often more questions raised than answered, and it is up to the reader to add meaning and potential applications of the ideas and categories in the chapter to the complexity of the "world out there" where decisions are made and people need to have food. 


\section{An Integrated Approach to Livestock Farming Systems' Autonomy in Designing and Managing Agroecological Transition at the Farm and Territorial Levels}

Challenges in agriculture that have arisen as a result of the wide application of industrial agricultural technology are clearly described in the introduction to this chapter on integrated farming practices, using agroecology as a guide at different levels of hierarchical scale.

An important contribution of the chapter is the focus on hierarchy of scale, with emphasis moving from farm level to landscape or "territory", and the discussion of collective action in planning and decision making is valuable. There is careful attention to the issues of resilience and autonomy, and an appropriate perspective of examining organisation at the "territory" level in contrast to most analyses that are done at the farm or regional levels. Several key concepts from agroecology include closing cycles, using biotechnical autonomy as a guide to management, and coordinating organisational strategies at each appropriate scale. The terms of levers or positive forces and locks as those that may impede progress provide a useful classification similar to what others call a "force field analysis" in development. A key to success is seen in the integrated efforts of players in the area, and how these are much more useful in causing lasting and sustainable change than when farmers act alone.

To illustrate the principles a case study of production of sheep milk is presented in detail. The participatory approach to identifying key forces is shown through figures and tables developed by the farmers in the area, and they begin with the typical cataloguing of biophysical components and activities and their principal interactions. Perhaps the most compelling information relates to the organisational activities and how these are essential to success. This is an important contribution because of its focus at the "territory level" and the emphasis on people working together for the good of the community. The chapter is long and repetitive in English, but the ideas are sound and will prove valuable to interested readers.

\section{Agroecological Transition from Farms to Territorialised Agri-food Systems: Issues and Drivers}

Any transition from the current dominant industrial system to one that is guided more by agroecological principles and practices must consider the reality that any transformation is often more impacted by markets, including influence of support programs, and regulations at different levels in the spatial hierarchy. Transformations at levels above the farm are more difficult because of the number of additional stakeholders and influences at the "territory" or larger geographic area. For this reason, the authors emphasise the need for transitions and incremental changes 
rather than a "new revolution". This point would be debated by some who feel frustrated by the inertia of the current agri-business and market-driven paradigm in food systems, and the need for a more global "transformational change". In our view there is a need for a revolution, but that this should be a "revolution in the mind", to be followed by a "transition in the field".

The authors categorise potential changes into "weak" and "strong" transitions, with the latter characterised by more radical modifications, substantial increases in system biodiversity, and the need to focus on what will lead to long-term sustainability in the whole food system. They rightly point out that this must engage farmers and broader-based groups at territory level to make meaningful change. What sets the chapter apart is emphasis on need for change in basic values, as these inform not only attitudes but also individual practices or crops or animal species. Many of our programs are imbedded in a current culture that is "locked in" to establish systems that in fact hinder creativity needed to make change. There is such an investment in the currently modal industrial paradigm, and so many vested commercial interests that depend on the status quo for short-term financial gain, that change is extremely difficult. We find in teaching, especially among undergraduates in the agricultural sciences, that there is a "monoculture mentality" that pervades the thinking of many. And with our farmer clients some of the same attitudes prevail. To be sure, there is value in conservatism and resistance to change, especially as the climate and economic future remain so uncertain and profits are narrow in agriculture. But one of the clear options presented in the chapter is to think and make decisions at spatial scales larger than the farm, and to cooperate at the territory or landscape levels. This will benefit everyone, rather than just a few, and help to sustain our rural families as well as their communities.

\section{A Plurality of Viewpoints Regarding the Uncertainties of the Agroecological Transition}

One of the many challenging problems of the present "command and control" industrial model of agricultural management that makes it untenable for the longterm future is an inability to deal with uncertainty and ambiguity, as well as not providing flexibility to handle situations of imperfect and incomplete information. In addition to this thesis presented in the chapter, we would add the complexity of incommensurate goals among the multiplicity of players in today's agriculture and food system environment. The authors appropriately point to the importance of adaptive management to deal with what they term a "diversity of uncertainties". They further describe decisions with incomplete information as "wagers on the future", a compelling introduction to what is developed as a treatise on how agroecology and systems thinking can solve these seemingly intractable problems.

The chapter explores the inadequacy of well-meaning but simple productionconsumption approaches, here placed in the category of "weak ecological models" as practiced by small and select groups of practitioners that depend on accumulation 
of information on today's reality to support action in development. The authors propose that "strong ecological models" are essential, involving a wide group of actors, and incorporating ways to recombine knowledge that are relevant across the temporal and spatial continua. For example, they point out that merely increasing technological efficiency is useful but not sufficient to explore the consequences of uncertainty, and that experiments that combine biophysical elements with social behaviour and decision making are needed to develop new and effective models for the future.

The authors describe the well-known food chains from production to consumption, and explain the "contractual chains" that guide their organisation. We suggest that the concepts of "food chains" or even "value chains" could logically be replaced by "food webs" and "value webs" in our quest to apply ecological principles to design and management of food systems. Further, we suggest that the authors consider the current thinking about vertical integration in supply chains as a neoclassical construct similar to much of our linear thinking in describing systems. It could be more transformative to again insert the term "webs" and to conceptualise lateral, vertical, and multiple dimensions of integration in the interactions of inputs, outputs and socioeconomic consequences of food systems, such as equitable distribution of benefits, as a broader way to think beyond the typical biophysical components and short-term outputs of a system.

When considering "sensemaking in management" the authors describe the importance of dealing with and reducing ambiguity, yet realise how this in itself may not reduce misunderstandings of system function. Reduction of ambiguity through increased transdisciplinary activity might help stakeholders to move towards an understanding of the situation as a whole. The authors point out the importance of considering who are the participants, what are their goals, what is the relevant place or territory, how does one establish a relevant time frame, and what are the most important criteria for evaluating a system. This leads to discussion of the value of modelling, using solid data on systems, probabilities of conditions such as weather and economics, and other parameters that drive the systems. They also describe the difficulty of incorporating ecoservices into the models, often not clearly defined and even more often not monetised, and the challenges of deciding what outcomes to optimise. The chapter does a good service to the reader by raising many questions. This is often more difficult that providing clear answers, but that is the nature of dealing with ambiguity, resulting from disciplinary specialisation.

\section{Towards an Integrated Framework for the Governance of a Territorialised Agroecological Transition}

The introduction makes two key points, that shared and participatory governance is a key factor in preventing excesses of influence by one leader or a small group of influential interests, and that critical issues include the recognition of system boundaries, generally spatial/geographic, and identification of the players or stakeholders 
who are included. The authors recognise a major challenge to be the willingness of leaders and all players to dedicate enough time and energy, as well as the resources needed, to design and implement an effective form of governance that will help everyone in the territory realise a relevant and transformative transition. They note the importance of recognising importance of both the" Socio Ecological System (SES)" and the"Socio Technical System (STS)" and the vital need to seek convergence of the two in promoting a successful Territorialised Agroecological Transition (TAET).

The chapter continues with discussion of the complexity of designing governance to encourage TAET when there are multiple goals, and with the difficulty of measuring most ecoservices. There are options that include both incentives (payments) or sanctions (penalties) for adopting new practices, and education that leads to a positive approach is certainly favourable as a strategy more palatable to stakeholders. The mix of market incentives with certain regulations provides wide opportunity for creative alternatives in policy, and the authors suggest that a "reflexive approach to governance" that includes negotiation and involvement of all stakeholders will assure a smoother route to adoption. There is recognition of the importance of regular communication and the need to suppress power relationships, and we think that these are especially critical when vested political and financial interests come into the equation.

Lastly and perhaps most important is attention in the chapter to a higher order issue, and that is interest in both the results of creative governance and the process of getting there. In any educational endeavour, the value of process cannot be underestimated as this is what will prepare people to deal with uncertainty in the future, whether this is in deciding on farming practices, methods of local marketing, or strategies for the formidable and transformative activities in implementing TAET. The authors conclude that "environmental, economic, and social processes do not stop at the boundaries of a given territory" and that the recognition of flows of materials, connections to markets, and many interdependencies require a scaling up of thinking and establishing connections. Perhaps the term "right scaling" would be preferable to "up or down" scaling, as this will be unique to a given territory and its circumstances. As more is learned about how to quantify and reward ecoservices, and environmental impacts are better understood, it will become increasingly apparent that the marketplace is not the only or perhaps even the primary factor driving the system. The process of governance will take this into account in the future, and the results will be territory-specific.

\section{The Key Role of Actors in the Agroecological Transition of Farmers: A Case-Study in the Tarn-Aveyron Basin}

There is an immediate dichotomy established between those who support and those who oppose AET, a useful but simplified description of reality. We often find an array of interests that fall on a spectrum between the extremes. And a critical 
observation at the outset is that a mere fraction of research funding has been spent on agroecology approaches. Thus any comparison of the systems must take into account the paucity of data that is essential to improve practices using ecological principles. The authors rightly recognise that increasingly our systems are hybrids of the extremes, and that thoughtful farmers are using ideas from both. The two extremes can be summarised as the authors said, that one group considers agroecological methods as moving back to the past, while proponents describe this as moving into the future. We agree with the latter, of course recognising the value of knowing about past experiences, especially from the pre-industrial era.

In contrast to other chapters based primarily on the literature, this one is partly based on empirical data derived from interviews with farmers, with results used to explore the importance of past experience as well as how they see the current networks helping to move toward TAET. One in-depth interview provided insight on a conventional farmer who cited his large investment in the technology paradigm, and who saw no rational reason to change. Another provides a profile and history of an active group member who is making the transition, and has experienced ups and downs during the process. He is working toward autonomy and takes a long-term view, while considering himself a "technical farmer" who has embraced the philosophy of agroecology including strong respect for the environment. In the second year of the study the focus was on food systems, especially ways to add value to products before sale. Here is where contacts and support in the groups were seen as vital to getting information and finding new and practical ideas. In summary the authors describe the importance of major conventional farmers and marketing organisations in hindering progress toward goals of introducing agroecology, yet the number of farmers moving in this direction demonstrates its viability economically and its consistency in agroecology principles. This conclusion is similar to what we have observed in Norway and elsewhere, that the move toward transformational change is a powerful one and is stimulated by a number of educational programs in universities and practical training activities in agriculture.

\section{Participatory Methodology for Designing an Agroecological Transition at Local Level}

The next major section of the book deals with recommended methods and tools for the TAET, the importance of reflection and evaluation during the process, and the details of the TATA-BOX approach. The ideas here are based on the previous chapters, and are meant to provide a "road map" to implementation. This chapter describes an essential and complex "co-evolution of technical, social, economic, and institutional dimensions" that is highly dependent on close interactions between "stakeholders in the farming system, supply chain, and natural resources management". The consistent emphasis through the book is on local control and commercialisation, and the dependence to the degree possible on natural and renewable 
resources. As in other chapters, there is focus on importance of integration of efforts through interdisciplinarity and systems thinking promoted by having multiple stakeholders and their ideas represented in the process.

Discussion of implementation starts with the goals of the TATA-BOX tools designed to implement the switch from "AET design theory to operational and effective practices". As described in the introduction, the strategy is organised around three domains: the farming system, the socio-technical system involving supply chains, and the socio-ecological system involving territorial resource management. Illustrative figures build understanding of the relationships among these elements. The design process is familiar to us because it is similar to that used in our Agroecology MSc course in student project teams: observe and evaluate current resources, develop visions of a desired future, designing a more desirable future as a result of transformative changes, exploring alternative pathways to reach that future, and implementing a governance strategy to guide the process, as illustrated in Fig. 2.

What contributes to making this perhaps the most valuable chapter in the book is the highly accessible step-by-step process in the development of the TATA- BOX method itself. Accompanied by multiple illustrations, the text transforms a case study in transformative development of a new model into practical language and a logical pathway to apply the method in other situations and territories. It is useful to theorise about change and learn from the literature about experiences of others, but far more valuable to walk through the steps that were used to develop the method described in this book. A number of practical tools are described that were essential parts of the participatory workshops, specific ideas about how to organise focus groups, foster as much participation and ownership as possible, and then move into the implementation of the whole process.

Operational outcomes of the model development workshops included the shared diagnosis of the current situation, the agreed-on goals of the overall project, and specific steps in the action plan as well as a framework for project governance. There is careful thought given to the a priori anticipated outcomes and impacts, providing another opportunity to fine-tune the process to help reach common goals. Four workshops were used to reach the eventual, shared-agenda action plan, with the last workshop organised partly by the stakeholders. Although the process appears long and complex, we agree that this is perhaps the most important part of the entire exercise. The chapter on tools and implementation concludes with asking key questions about the process and how it could be improved. Lastly, the workshops resulted in "ready to use outputs for local stakeholders", most importantly a shared diagnosis for 2015 and a vision for 2025 of the new territorial plan and a projected action plan to get there. The process represents one described by futurist Joel Barker two decades ago: "Vision without action is merely a dream. Action without vision just passes the time. Vision with action can change the world". 


\section{Towards a Reflective Approach to Research Project Management}

This chapter steps back to take another look at the process used to arrive at the TATA- BOX. It describes the design of AETs to promote transformational changes in agriculture and food systems, with the full participation of local stakeholders. On another level the process includes designing a participatory methodology to define those transitions and a plan to achieve them. Lastly the process includes design of a governance strategy to oversee and catalyse transitions. This chapter outlines how project advisors worked with leaders to reflect on their success and how to continue improvement.

The authors begin with review of the literature on management of activities, and of the design process itself, citing the value of "Activity-Centred Ergonomics" as a proven method of engaging players in reflective thought about their own organisational actions. They describe a series of meetings, each with its own goals, that leads to an iterative strategy of evaluation. First is a diagnosis of project management, an assessment of how things are proceeding. This includes identifying key issues, then evaluating how the reflective process helped to resolve them, and an evaluation of how the process worked. A number of quotes from participants enrich the discussion with personal opinions about their experience in the workshops. Most were supportive, while others made specific suggestions on how to improve the process. Although most of them reported success in many ways, one conclusion was that the reflective process was not robust enough to solicit enough people for feedback, and a concern that not all voices were heard.

\section{Evaluation of the Operationalisation of the TATA-BOX Process}

An important feature of this book on the TATA- BOX tool and the process through which it was derived is the focus on development of the tool as a case study itself, a process that "can be defined through two main features: it is participatory and it is intended to support design". Also important is the willingness of the editors and authors to evaluate the implementation of the process through this unique tool. They have chosen "design process evaluation frameworks" from the literature, using metrics that were developed for other applications but here applied to changes in farming and food systems based on agroecology principles.

Semi-structured in-person interviews were conducted with participants in the process to explore expectations regarding workshops and then impressions of how they went, the workshop results, how the process related to other parts of tool development, and the interpretation and eventual influence on territorial development. 
General reaction to the workshops was positive, with some critique about overrepresentation by INRA specialists and need for more representatives from the case territory. Specific tools used in conducting the workshop were viewed as valuable, and participants felt that their voices were heard. There were positive comments about the facilitators, participants felt that the results were objectively summarised and reported, and only a minority of those interviewed felt that the process had not been adequately completed. About half reported that they had learned valuable information and process, and had used this in their own work. Quotes from participants add rich detail to the summarised data from the interviews.

Workshop participants generally felt that there was good communication, and that a wide range of views were expressed and reflected in the report. There was less agreement on the value of the outputs, and how these would result in concrete actions to achieve the stated goals of the project. It was difficult to tell from the summary how enthusiastic the workshop participants were about the entire process, and they seemed to take a "wait and see" attitude about the long-term results of the TATA- BOX tool and methods. From this we conclude that the exhaustive process of multiple workshops, careful design of theoretical constructs for classifying people, places and their characteristics, human intentions, and actions may have been less successful that what was hoped by the organisers. There is no consistent evidence that a state of "shared governance" had been achieved in these workshops that generally were organised and administered in a "top-down" manner, one that contradicts one of the basic tenets of the plans for the entire project. Of course it is difficult to assess success of the venture until the tools are applied in multiple places, and there is a more comprehensive evaluation of outcomes.

\section{Information and Communication Technology (ICT) and the Agroecological Transition}

Rapidly expanding capabilities and accessibility of information and communication technologies (ICT) provide a number of tools for the design and implementation of a truly transformative change in agriculture and food systems. Among the capabilities are computer support for multi-criteria guidance in design, constructing and implementing research frameworks, and communication potentials for improved networking with stakeholders. Authors raise the intriguing question, is ICT a useful tool or an invitation to slavery once a person or system is wedded to this technology? We ask further whether this is a viable tool that can be used when appropriate and available, or is it a set of clever technologies that were expensive to develop and with companies searching for applications to pay for the investment? Most of us in science and development agree that there are countless advantages to the computational and communication capabilities of ICT, and few would question our dependence on the equipment and software that currently pervade our workplaces and our 
lives. We often find it difficult to imagine how we accomplished anything without these tools at our fingertips.

The chapter introduces the term "connected agriculture" to encompass the myriad devices and apps now at our fingertips that allow us to monitor soil moisture and nutrients as well as keep current on local and distant markets and prices, as well as computer updates from purveyors that "most assuredly" would enhance our efficiency and output if we would just "buy the new app". It appears to us that these new tools do indeed facilitate our conceptualising new systems and assessing their potential outcomes in ways that were previously unknown and impossible. Thus the tools could comprise a new model for agriculture based on instant communication and access to the widest possible range of information, and the challenge soon becomes how to interpret this avalanche of data and to glean those few nuggets of wisdom useful to us in designing biodiverse production systems that result in healthy food for the community. ICT provide tools that help connect these nuggets not only for integration of local resources in agroecologically sound farming systems, but to scale these up to watershed and landscape level, collectively called sustainable territorial systems.

ICT is such a large and pervasive presence in today's global economy and community, and is important to each unique location and the design of systems for each place. Among the key issues that stand out in the chapter are the need for an open infrastructure and equal access by all to the power of the internet, related to this the importance of reducing costs of access, and exploiting potentials of adapting power of ICT to local situations, cultures, and constraints, all critical to specific needs in each territory. There is discussion of how open access to capacities of ICT can facilitate the building of consensus in communities of shared interest, and also to facilitate the shared governance described in other chapters. At the same time, ICT capabilities provide potential for tapping into, recording, and integrating diversity of opinions and goals, so that communities and territories can design strategies to meet multiple needs in an equitable way. Among these tools are communications strategies, functional tools that digitise information to improve access, and both data management and decision support systems. Lastly the chapter explores costs and benefits of ICT, and speculates on future applications that will result from this everexpanding electronic network.

This brief summary barely skims the depth of ideas presented in the book, and especially in the complex and growing world of ICT. As educators, researchers, and development specialists we are hard pressed to keep up with new technologies; often our students are our teachers, as they are "natives in the complex information environment, while many in our generation are "immigrants in this new land". While we may lag in understanding the bells and whistles of current ICT, those with experience have a special obligation to help younger colleagues seek meaning and wisdom from the oceans of data now available. We expand on this is the overall summary section. 


\section{TATA-BOX: Summary and Critique of Tools for Transformational Agroecology in Development}

After reading and reviewing the chapters, we have learned much more about the importance of organising participatory strategies to organise, administer, implement, and evaluate a transformative process toward agroecological farming and food systems. The book has valuable information and is clearly written. As this is being published in English, we assume that it is directed toward an international audience interested in agroecology, and providing guidelines to others for improving sustainability and autonomy of food systems at the territory level. While the text is very well written, there are places where it is repetitive, for example when introducing each chapter with much of the same information about the negative impacts of industrial-model farming and food systems. We recommend that readers should skim parts of some chapters to glean what is important, a strategy that will help avoid "reader fatigue". Some of the categorisation and analysis is described in more detail than needed to apply the model.

The small shortcomings in writing do not diminish the valuable ideas about agroecological focus for development. The principles of holistic systems thinking, local and broad involvement of multiple stakeholders, autonomy in production linked to consumption in local food systems, and broad-based governance at territory level bring together biophysical and socioeconomic dimensions of production and consumption of food. These all reflect the current writings about agroecology as a viable organising framework for agriculture, and the importance of involving all the players in planning future directions. When all stakeholders assume ownership of the process, it is much more likely that transformative alternatives will be developed and adopted. These need to consider the goals of all participants, the available local resource base, and the production, economic, environmental, and social implications and outcomes of any new strategy. We commend the authors of this book, and look forward to following the results as the applications of the TATA-BOX model are implemented.

\section{References}

Checkland P, Scholes J (1999) Soft systems methodology in action. Wiley, New York

Francis C, Lieblein G, Gliessman S et al (2003) Agroecology: the ecology of food systems. J Sustain Agric 22:99-118. https://doi.org/10.1300/J064v22n03_10

Francis C, Østergaard E, Nicolaysen A et al (2016.) Learning agroecology through Involvement and reflection) Agroecology: a transdisciplinary, participatory and action-oriented approach. In: Mendez V, Bacon CM, Cohen R, Gliessman SR (eds) Advances in agroecology series. CRC Press, Boca Raton, pp 73-99

Lieblein G, Francis CA, Torjusen H (2001) Future interconnections among ecological farmers, processors, marketers, and consumers in Hedmark County, Norway: creating shared vision. Hum Ecol Rev 8:60-71 
Lieblein G, Østergaard E, Francis C (2004) Becoming an agroecologist through action education. Int J Agric Sustain 2:147-153. https://doi.org/10.1080/14735903.2004.9684574

Ostrom E (2009) A general framework for analyzing sustainability of social-ecological systems. Science 325:419-422. https://doi.org/10.1126/science.1172133

Wezel A, Bellon S, Doré T et al (2009) Agroecology as a science, a movement and a practice. A review. Agron Sustain Dev 29:503-515. https://doi.org/10.1051/agro/2009004

Open Access This chapter is licensed under the terms of the Creative Commons Attribution 4.0 International License (http://creativecommons.org/licenses/by/4.0/), which permits use, sharing, adaptation, distribution and reproduction in any medium or format, as long as you give appropriate credit to the original author(s) and the source, provide a link to the Creative Commons licence and indicate if changes were made.

The images or other third party material in this chapter are included in the chapter's Creative Commons licence, unless indicated otherwise in a credit line to the material. If material is not included in the chapter's Creative Commons licence and your intended use is not permitted by statutory regulation or exceeds the permitted use, you will need to obtain permission directly from the copyright holder.

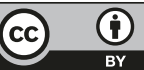

